\title{
Kidney Disease in Life-Course Socioeconomic Context: The Atherosclerosis Risk in Communities (ARIC) Study
}

\author{
David A. Shoham, PhD, Suma Vupputuri, PhD, Ana V. Diez Roux, MD, PhD, \\ Jay S. Kaufman, PhD, Josef Coresh, MD, PhD, Abhijit V. Kshirsagar, MD, MPH, \\ Donglin Zeng, PhD, and Gerardo Heiss, MD, PhD
}

\begin{abstract}
Background: Persons belonging to the working class or living in an adverse social environment at particular periods of their life course may have an increased risk of chronic kidney disease (CKD).

Methods: This hypothesis was examined among participants of the Life Course Socioeconomic Status Study, an ancillary study of the Atherosclerosis Risk in Communities Study, conducted in 2001 (mean age, 67.4 years; $N=12,631$ ). CKD was defined by hospital discharge diagnosis and/or estimated glomerular filtration rate less than $45 \mathrm{~mL} / \mathrm{min} / 1.73 \mathrm{~m}^{2}\left(<0.75 \mathrm{~mL} / \mathrm{s} / 1.73 \mathrm{~m}^{2}\right)$. Social class was categorized as working class or non-working class at ages 30,40 , or 50 years. Area-level socioeconomic status was based on a composite of census scores during the same period. Adjusted odds ratios were obtained within strata of white and African-American race.

Results: The adjusted odds ratio of CKD for persons belonging to the working class versus non-working class at age 30 was 1.4 (95\% confidence interval, 1.0 to 2.0$)$ in whites and $1.9(95 \%$ confidence interval, 1.1 to 3.0) in African Americans. Working class membership was associated with CKD, even at earlier stages of adult life, and class was associated more strongly with CKD than was education. Working class membership also suggested a stronger association with CKD among African Americans than whites, independent of diabetes and hypertension status. At later periods in the life course, area socioeconomic status was associated with CKD.

Conclusion: Socioeconomic factors, including area socioeconomic status and social class, are associated with CKD and may account for some of the racial disparity in kidney disease. Am J Kidney Dis 49:217-226. (C) 2007 by the National Kidney Foundation, Inc.
\end{abstract}

INDEX WORDS: Kidney diseases; residence characteristics; social class; continental population groups.

$\mathbf{E}$ nd-stage renal disease (ESRD) has become an epidemic during the last 30 years; the number of cases in the United States is now more than 400,000, with incidence of approximately 100,000 new cases per year. ${ }^{1}$ The economic and personal costs of ESRD have prompted investigation of earlier stages of chronic kidney disease (CKD). CKD is associated not only with progression to kidney failure, but also with cardiovascular disease morbidity and mortality. ${ }^{2,3}$ Recent estimates reported early CKD (stages 1 to 4 ) prevalence to be as high as $11 \%$ in the general population, and it is described as a silent epidemic in the United States. ${ }^{4-10}$

The social determinants of CKD have received little attention, and no study has investigated the role of socioeconomic circumstances during the entire life course in the development of CKD. ${ }^{11,12}$ Most work on the social determinants of kidney disease in the United States
From the Departments of Epidemiology and Biostatistics, School of Public Health, and UNC Kidney Center, University of North Carolina, Chapel Hill, NC; Department of Epidemiology, School of Public Health, University of Michigan, Ann Arbor, MI; and Department of Epidemiology, Bloomberg School of Public Health, Johns Hopkins University, Baltimore, $M D$.

Received June 23, 2006; accepted in revised form November 9, 2006.

Originally published online as doi:10.1053/j.ajkd.2006.11.031 on January 3, 2007.

Support: D.A.S. is currently supported by an institutional National Institutes of Health (NIH)-National Heart, Lung, and Blood Institute (NHLBI) postdoctoral training grant in cardiovascular disease epidemiology, 5T32HL007055-29, and was supported by an institutional training grant in renal epidemiology, 5T32DK007750-07. D.A.S. and S.V. were supported by NIH-National Institute of Diabetes and Digestive and Kidney Diseases R21DK68354-01A1. A.V.D.R. was supported in part by R24 HD047861 (CHUMS). The ARIC Study is conducted and supported by the NHLBI in collaboration with ARIC study investigators. Potential conflicts of interest: None.

Address reprint requests to David A. Shoham, PhD, UNC Kidney Center, CB\# 7156, Chapel Hill, NC 27599-7156.

E-mail: shoham@email.unc.edu

(c) 2007 by the National Kidney Foundation, Inc. 0272-6386/07/4902-0007\$32.00/0

doi:10.1053/j.ajkd.2006.11.031 
focused on the role of African-American race. ${ }^{12,13}$ Racial identity reflects a complex interaction of genetics, geographic origin, skin color, cultural ancestry, and socioeconomic conditions. Although racial differences in disease rates led some to search for genetic explanations, socioeconomic differences by race are more likely to provide explanation for disparities between populations. ${ }^{14}$

The measure of social position used in most epidemiological studies is a form of continuous socioeconomic status (SES), such as education level and income. Epidemiological studies rarely assessed social class, defined as the place individuals occupy in power or authority relationships in the workplace. ${ }^{15-17}$ Nevertheless, social class was shown to be a powerful predictor of coronary heart disease, hypertension, cancer, and all-cause mortality. ${ }^{18-20}$ Social class also offers a firmer theoretical underpinning for the study of social patterns of disease in populations because social class may determine such diverse characteristics as income level, education, psychosocial stress, and health behaviors, habits, and lifestyle. ${ }^{17,21,22}$ It is argued that social class is superior to continuous SES measures because class uses power relationships to explain how inequalities are generated and maintained. ${ }^{17,23,24}$

In addition to class membership, individuals are embedded in geographic and historical contexts. ${ }^{25,26}$ Adverse social conditions measured at the census-tract level were associated with diverse outcomes, including coronary heart disease, ${ }^{27}$ low birth weight, ${ }^{28,29}$ and lead poisoning. ${ }^{28}$ Socioeconomic life-course research extends context by examining social conditions during a lifetime. ${ }^{30,31}$ Researchers, including Barker, ${ }^{32}$ argued that there are critical periods early in human development in which risk of adult disease may be acquired. We investigate whether individual social class, education level, or area-level socioeconomic resources in childhood and adulthood are associated with increased risk of adult kidney disease. We further assess the extent to which diabetes and hypertension account for any associations observed.

\section{METHODS}

Subjects were members of the Life Course Socioeconomic Status (LCSES) ancillary study of the Atherosclerosis Risk in Communities (ARIC) Study. Details of the ARIC
Study were published elsewhere. ${ }^{33}$ Briefly, the ARIC Study is a longitudinal cohort study of 15,792 white and AfricanAmerican men and women residing in 4 communities: Jackson, MS; Forsyth County, NC; the suburbs of Minneapolis, MN; and Washington County, MD. ${ }^{33}$ At the time of recruitment (1987 through 1989), subjects ranged in age from 45 to 64 years. After a baseline visit, 3 more examinations were conducted, at 3-year intervals.

Serum creatinine measures were obtained from 15,715 subjects during at least 1 of 3 visits. Follow-up information for hospital discharge diagnoses also was obtained and confirmed through 2002.

The LCSES was designed as a retrospective cohort. This study was approved by the University of North Carolina Institutional Review Board. During the 2001 annual follow-up interview, subjects were asked questions about their own SES at ages 30, 40, and 50 years and parental SES at age 10 years. Participants also reported the addresses at which they had lived at ages $10,30,40$, and 50 years. These addresses were geocoded and placed in the appropriate census tract. At age 10, county was used instead of census tract because few areas of the United States were tracted at that time. The accuracy and repeatability of this geocoding process were reported. ${ }^{34}$

There were 12,716 subjects who answered the LCSES questionnaires. Exclusions because of insufficient numbers were made for participants who were neither white nor African American $(\mathrm{n}=35)$; for African Americans living in Minneapolis $(n=13)$ or Washington County, MD $(n=26)$; and for those missing at least 1 serum creatinine measure $(\mathrm{n}=11)$. The final analysis used data from 12,631 participants.

\section{Individual Socioeconomic Position}

Individual social class for a subject at ages 30, 40, and 50 years was obtained by using 5 questionnaire items: (1) "Did you complete education of college or more?" (2) "Were you self-employed?" (3) "Did you hold a managerial position?" (4) "Did you supervise the work of other employees?" and (5) "Did you participate in making decisions [at work]?" Subjects who answered "no" to all 5 questions were classified as working class; subjects who answered "yes" to at least 1 of these questions were classified as "non-working class" (the reference category). These questionnaire items were derived from Erik Olin Wright's class schema based on ownership, control, and skill level and were validated by Wright ${ }^{24}$ and used by other health researchers, albeit infrequently. ${ }^{15}$ Because the class status of homemakers is controversial, ${ }^{35}$ subjects who indicated they were homemakers at any of these ages were excluded from class analyses for that period; this proportion was greatest at age 30, when 2,802 white women $(54 \%)$ and 348 African-American women (18\%) reported being homemakers. A similar set of questions asked of subjects, in reference to their fathers when the subjects were children, was used to classify the father's occupation as working class and non-working class. Subjects' fathers also were dichotomized as farmers or nonfarmers. Secondary analyses were conducted using only subjects' and subjects' fathers' highest education levels; subject's education was coded as 0 to 11 years (less than high school), 12 to 15 years (high school graduate), and $16+$ years 
(referent; college graduate); father's education was coded as 0 to 8,9 to 11 , and $12+$ years of education (referent).

\section{Area-Level SES}

Area-level SES was assessed by linking the geocoded historic addresses of respondents with decennial census data. Area SES variables were measured at the county level for childhood (age 10 census years: 1930, 1940, and 1950) and at the census tract level for ages 30, 40, and 50 (census years: 1960 to 2000). To create an overall score for arealevel SES exposure, a principal components analysis of area-level SES attributes was conducted for each decennial census. Up to 15 variables were used in the principal components analysis (depending on census year), including log median home value, log mean income level, unemployment, number of people living per room, percent high school and college educated, percent professional, and percent home ownership. $z$ Scores were created by subtracting the mean value for a particular census variable on a given census year from the value for a particular subject's county or census tract, then dividing by the SD. The first component loadings from the principal components analysis were used to generate a weighted sum of $z$ scores at each age. These were loaded most heavily by 4 neighborhood characteristics across all years: $\log$ household income, percent professional or managerial occupations, percent with at least a high school education, and log of mean home value. This score represents the socioeconomic resources of the neighborhood, rather than family structure components or housing characteristics.

\section{Outcome Measure}

The outcome used in these analyses was CKD, defined by either an estimated glomerular filtration rate (GFR) less than $45 \mathrm{~mL} / \mathrm{min} / 1.73 \mathrm{~m}^{2}\left(<0.75 \mathrm{~mL} / \mathrm{s} / 1.73 \mathrm{~m}^{2}\right.$; estimated from the abbreviated Modification of Diet in Renal Disease [MDRD] equation ${ }^{36}$ ) or an International Classification of Diseases, Ninth Revision (ICD-9), annual hospital discharge diagnosis of CKD (see Appendix for ICD-9 codes). The most recent serum creatinine measurement available was used to estimate GFR. Serum creatinine measures were standardized to the MDRD Cleveland Clinic laboratory values indirectly by using a calibration constant of -0.24 $\mathrm{mg} / \mathrm{dL}$ for visits 1 and 2 and $+0.18 \mathrm{mg} / \mathrm{dL}$ for visit $4 .^{37}$ Based on the work of Go et al, ${ }^{38}$ we chose a GFR cutoff value of $45 \mathrm{~mL} / \mathrm{min} / 1.73 \mathrm{~m}^{2}\left(0.75 \mathrm{~mL} / \mathrm{s} / 1.73 \mathrm{~m}^{2}\right)$.

\section{Statistical Analysis}

Multiple imputations were conducted to handle issues of missing data by using a Bayesian Gibbs sampling algorithm. The resulting imputations were used in all further analyses. Model specifications for the imputations are given in the Appendix.

Characteristics of the study population were examined by using mean \pm SD for continuous variables and proportions for categorical variables. Logistic regression was used to calculate the odds of CKD in persons who were working class members compared with those who were non-working class members at each life-course period. Similar contrasts were drawn for subject's father having been a member of the working class compared with non-working class. The arealevel measure of SES was specific to the life-course period in the model; thus, census tract at age 50 was included in models with subject's class status at age 50 .

Because of clustering of subjects within census tracts, a random intercept model was chosen. This model treats each census tract or county's intercept as randomly drawn from a normal distribution. All analyses were conducted using SAS, version 9.1 (SAS Institute, Cary, NC).

Three logistic models were compared: model 1 included age at visit 1 as a covariate; model 2 included age at visit 1 , sex, area SES, class, father's class, and center; and model 3 included all model 2 covariates, with the addition of diabetes and hypertension at initial ARIC visit. In model 3, adjustment is made for these potential causal intermediates to estimate the direct effect of social factors on kidney disease and measure its attenuation upon adjustment for potential mediators. Models were fit within strata of white or AfricanAmerican race. Attenuations are reported in percent reductions in the log odds and compared with age-adjusted odds ratios (ORs) unless otherwise noted. Model fit was assessed by using likelihood ratio tests comparing the -2 log likelihood estimates between fixed-effect-only versions of a simple model with age alone (model 1); a model adjusted for only the confounders age, sex, and study site (model 2); and model 2 adjusted further for diabetes and hypertension (model 3). To assess the heterogeneity of associations between SES and CKD by race, statistical interactions were assessed by including an interaction term for AfricanAmerican (versus white) race with working class or education level in models; $P$ greater than 0.10 for the interaction term is considered statistically significant evidence for the association differing between whites and African Americans.

Sensitivity analyses explored whether particular components of social class (such as being self-employed or supervising others) were associated with kidney disease and whether there was a dose-response of decreasing risk with increasing number of social class components. To investigate sensitivity of findings to heterogeneous outcome definitions, multivariate models for social class were run using outcomes based on only GFR or only ICD-9 code. Because this population was relatively old and both CKD and lower socioeconomic position may predispose subjects to death before they could have responded to the LCSES questionnaire, analyses were repeated using subject's education level (no high school versus some high school or more), which was available for all subjects. This allows quantification of the impact of mortality, which is a competing risk that may bias results.

\section{RESULTS}

Prevalences of CKD, defined as GFR less than $45 \mathrm{~mL} / \mathrm{min} / 1.73 \mathrm{~m}^{2}\left(<0.75 \mathrm{~mL} / \mathrm{s} / 1.73 \mathrm{~m}^{2}\right)$, were $1.1 \%$ (105 cases) among whites and $1.4 \%$ (46 cases) among African Americans (Table 1). There were 758 whites $(8.0 \%)$ and 175 African Americans $(5.5 \%)$ with a GFR less than $60 \mathrm{~mL} / \mathrm{min} /$ $1.73 \mathrm{~m}^{2}\left(<1.00 \mathrm{~mL} / \mathrm{s} / 1.73 \mathrm{~m}^{2}\right)$, corresponding to 
Table 1. Mean Values and Proportions of Subjects' Clinical and Behavioral Characteristics by Race and Disease Status

\begin{tabular}{|c|c|c|c|c|c|c|c|c|}
\hline & \multicolumn{4}{|c|}{ White } & \multicolumn{4}{|c|}{ African American } \\
\hline & $\begin{array}{c}\text { Overall } \\
(n=9,449)\end{array}$ & $\begin{array}{l}\text { Noncases } \\
(n=9,230)\end{array}$ & $\begin{array}{l}\text { Cases }^{*} \\
(n=219)\end{array}$ & $P$ & $\begin{array}{c}\text { Overall } \\
(n=3,182)\end{array}$ & $\begin{array}{l}\text { Noncases } \\
(n=3,027)\end{array}$ & $\begin{array}{l}\text { Cases }^{*} \\
(n=155)\end{array}$ & $P$ \\
\hline Body mass index, visit $1\left(\mathrm{~kg} / \mathrm{m}^{2}\right)$ & $27.0 \pm 2.1$ & $26.9 \pm 4.8$ & $29.0 \pm 6.2$ & $<0.01$ & $29.8 \pm 2.7$ & $29.7 \pm 6.1$ & $31.9 \pm 6.2$ & $<0.01$ \\
\hline \multicolumn{9}{|c|}{ High-density lipoprotein, visit 1} \\
\hline Age, visit $1(y)$ & $53.9 \pm 5.6$ & $53.8 \pm 5.6$ & $57.1 \pm 4.9$ & $<0.01$ & $52.8 \pm 5.7$ & $52.8 \pm 5.6$ & $54.5 \pm 5.8$ & $<0.01$ \\
\hline Male sex (\%) & 45.6 & 45.5 & 48.9 & 0.70 & 35.3 & 35.3 & 36.4 & 0.81 \\
\hline Diabetes at visit 1 (\%) & 7.4 & 6.9 & 29.3 & $<0.01$ & 16.1 & 14.3 & 52.1 & $<0.01$ \\
\hline Hypertension at visit 1 (\%) & 25.4 & 24.7 & 47.3 & $<0.01$ & 54.3 & 53.1 & 76.2 & $<0.01$ \\
\hline Diabetes and hypertension (\%) & 3.3 & 2.9 & 17.1 & $<0.01$ & 11.1 & 9.5 & 42.0 & $<0.01$ \\
\hline Current drinker (\%) & 65.4 & 65.8 & 53.4 & $<0.01$ & 29.7 & 30.0 & 21.9 & 0.04 \\
\hline Current smoker (\%) & 21.2 & 21.1 & 24.0 & 0.49 & 25.7 & 25.5 & 27.7 & 0.55 \\
\hline \multicolumn{9}{|l|}{ Prevalent kidney disease } \\
\hline$I C D-9(\%)$ & 1.6 & & & & 4.5 & & & \\
\hline \multicolumn{9}{|l|}{ MDRD GFR $<45 \mathrm{~mL} / \mathrm{min} /$} \\
\hline $1.73 \mathrm{~m}^{2}$, last visit (\%) & 1.1 & & & & 1.4 & & & \\
\hline \multicolumn{9}{|l|}{ MDRD GFR, baseline $(\mathrm{mL} / \mathrm{min} /$} \\
\hline $\left.1.73 \mathrm{~m}^{2}\right)$ & $89.5 \pm 7.7$ & $89.6 \pm 17.1$ & $80.8 \pm 20.9$ & $<0.01$ & $103.5 \pm 11.2$ & $103.9 \pm 24.6$ & $91.2 \pm 36.6$ & $<0.01$ \\
\hline
\end{tabular}

Note: Values expressed as mean \pm SD or percent. All nonage values are adjusted for mean age at baseline. To convert GFR in $\mathrm{mL} / \mathrm{min}$ to $\mathrm{mL} / \mathrm{s}$, multiply by 0.01667 ; high-density lipoprotein in $\mathrm{mg} / \mathrm{dL}$ to $\mathrm{mmol} / \mathrm{L}$, multiply by 0.02586 .

${ }^{*}$ Cases defined as subjects with GFR rate less than $45 \mathrm{~mL} / \mathrm{min} / 1.73 \mathrm{~m}^{2}$ at last visit and/or $I C D-9$ discharge diagnosis code for CKD.

Kidney Disease Outcomes Quality Initiative stages 3 to 5 (data not shown). ${ }^{39}$ Prevalences based on hospitalization discharge diagnosis were 149 (1.6\%) among whites and $142(4.5 \%)$ among African Americans. Among whites, 219 (2.3\%) met either case definition (GFR $<45 \mathrm{~mL} / \mathrm{min} /$ $1.73 \mathrm{~m}^{2}\left[<0.75 \mathrm{~mL} / \mathrm{s} / 1.73 \mathrm{~m}^{2}\right]$ or discharge diagnosis for CKD); among African Americans, the number was 155 (4.9\%; not shown). As listed in Table 1, whites and African Americans with CKD had higher values than noncases for body mass index, high-density lipoprotein cholesterol, and age, whereas prevalences of diabetes and hypertension were greater among cases than noncases in both race groups. Current alcohol consumption was lower in cases than noncases (all $P<0.05)$.

Table 2 lists socioeconomic characteristics of study participants, stratified by race and CKD case status and adjusted for age. Subjects with CKD tended to have lower educational attainment and area SES scores and were more likely to have been members of the working class at each age period. Education was statistically significantly different between cases and noncases among both races. Among whites, only working class status at age 40 was related significantly to CKD; among African Americans, working class status was associated with CKD at ages 30, 40, and 50. Area SES scores diverge between whites and African Americans during subsequent decades and were related significantly to CKD for age-50 area SES among both race groups.

Table 3 lists measures of association between social class and CKD. Model fit was best for model 3 at each life-course period $(P<0.001$ using the likelihood ratio test) versus a model with age as the only predictor. For age 50, model 2, which included all variables in model 3 except for diabetes and hypertension, fit significantly better than a model with baseline age as the sole predictor among both whites $(P=$ $0.035)$ and African Americans $(P=0.039)$. At other life-course periods, model 2 did not fit significantly better than a model with age as the sole predictor variable.

Among whites, father's social class or being a farmer does not appear to be associated with CKD. After adjusting for subjects' age, belonging to the working class at age 30 is modestly related to adult kidney disease, with 1.4 (95\% confidence interval $[\mathrm{CI}], 1.0$ to 2.0 ) times the odds of CKD as those who were not working class at age 30 . Further adjustment for area SES, father's social class and farming status, study site, and sex did not appreciably attenuate this 
Table 2. Age-Adjusted Socioeconomic Characteristics of LCSES Participants by Race and CKD Status

\begin{tabular}{|c|c|c|c|c|c|c|c|c|}
\hline & \multicolumn{4}{|c|}{ Whites } & \multicolumn{4}{|c|}{ African Americans } \\
\hline & $\begin{array}{c}\text { Overall } \\
(n=9,449)\end{array}$ & $\begin{array}{l}\text { Noncases } \\
(n=9,230)\end{array}$ & $\begin{array}{l}\text { Cases* }^{*} \\
(\mathrm{n}=219)\end{array}$ & $P$ & $\begin{array}{c}\text { Overall } \\
(\mathrm{n}=3,182)\end{array}$ & $\begin{array}{l}\text { Noncases } \\
(n=3,027)\end{array}$ & $\begin{array}{l}\text { Cases }^{*} \\
(n=155)\end{array}$ & $P$ \\
\hline \multicolumn{9}{|l|}{ Father without any high } \\
\hline $\begin{array}{l}\text { Father without high school } \\
\text { degree (\%) }\end{array}$ & 67.9 & 67.7 & 76.1 & 0.13 & 86.5 & 86.2 & 90.7 & 0.20 \\
\hline Subject without high & & & & & & & & \\
\hline school (\%) & 15.2 & 14.9 & 20.7 & $<0.01$ & 39.1 & 38.8 & 46.2 & 0.10 \\
\hline Subject without college (\%) & 61.4 & 61.2 & 69.9 & 0.02 & 68.3 & 67.9 & 77.2 & 0.01 \\
\hline Father was working & & & & & & & & \\
\hline class (\%) & 38.0 & 38.0 & 42.0 & 0.22 & 63.1 & 63.0 & 64.4 & 0.67 \\
\hline Father was farmer (\%) & 22.5 & 22.6 & 19.9 & 0.19 & 55.5 & 55.1 & 63.7 & 0.14 \\
\hline Working class at age $30(\%)$ & 39.3 & 39.1 & 48.5 & 0.09 & 58.1 & 57.3 & 72.1 & $<0.01$ \\
\hline Working class at age $40(\%)$ & 31.3 & 31.2 & 37.1 & 0.05 & 46.8 & 46.2 & 60.8 & $<0.01$ \\
\hline Working class at age $50(\%)$ & 26.6 & 26.5 & 30.9 & 0.31 & 40.0 & 39.9 & 53.8 & $<0.01$ \\
\hline Age 10 area score & $0.4 \pm 2.9$ & $0.4 \pm 2.9$ & $0.4 \pm 3.0$ & 0.34 & $-1.3 \pm 3.0$ & $-1.3 \pm 3.0$ & $-1.3 \pm 2.5$ & 0.76 \\
\hline Age 30 area score & $0.6 \pm 2.6$ & $0.6 \pm 2.5$ & $0.2 \pm 2.7$ & 0.30 & $-1.9 \pm 4.3$ & $-1.9 \pm 4.1$ & $-2.1 \pm 3.1$ & 0.74 \\
\hline Age 40 area score & $0.7 \pm 2.2$ & $0.7 \pm 2.2$ & $0.3 \pm 2.1$ & 0.16 & $-2.3 \pm 2.5$ & $-2.2 \pm 2.5$ & $-2.6 \pm 2.2$ & 0.23 \\
\hline Age 50 area score & $1.1 \pm 1.7$ & $1.1 \pm 1.8$ & $0.7 \pm 1.8$ & 0.01 & $-3.3 \pm 2.8$ & $-3.3 \pm 2.8$ & $-3.8 \pm 2.7$ & 0.05 \\
\hline
\end{tabular}

Note: Values expressed as mean \pm SD or percent.

${ }^{*}$ Cases defined as subjects with GFR less than $45 \mathrm{~mL} / \mathrm{min} / 1.73 \mathrm{~m}^{2}$ and/or $/ C D$-9 discharge diagnosis code for CKD.

relationship. Adjusting for hypertension and diabetes mellitus attenuated the age-30 social class by just $12 \%$. Similar associations were observed for social class at ages 40 and 50. Living in the lowest tertile of census tracts was associated with CKD only for age 50; after adjustment for age, sex, study site, and individual social class, the OR was 1.6 (95\% CI, 1.0 to 2.4). Further adjustment for hypertension and diabetes mellitus reduced the log-OR by $42 \%$ to $1.4(95 \% \mathrm{CI}$, 0.9 to 2.2 ).

African Americans show a similar pattern for social class and area SES as whites. The association of social class with CKD was strongest for age 30 , for which the OR is 1.9 (95\% CI, 1.2 to 3.0 ); the association was weakest for age 50 .

Table 3. ORs and 95\% Cls of CKD Using Social Class Definition

\begin{tabular}{|c|c|c|c|c|c|c|}
\hline \multirow[b]{2}{*}{ Adjusted for } & \multicolumn{3}{|c|}{ Whites } & \multicolumn{3}{|c|}{ African Americans } \\
\hline & Age & $\begin{array}{c}\text { Model } 2 \\
\text { Confounders }\end{array}$ & $\begin{array}{c}\text { Model 3: } \\
\text { Model } 2 \text { + Diabetes, } \\
\text { Hypertension }\end{array}$ & Age & $\begin{array}{c}\text { Model } 2 \\
\text { Confounders }\end{array}$ & $\begin{array}{c}\text { Model 3: } \\
\text { Model } 2+\text { Diabetes, } \\
\text { Hypertension }\end{array}$ \\
\hline Working class father & $1.2(0.9-1.6)$ & $1.1(0.9-1.5)$ & $1.0(0.8-1.4)$ & $1.2(0.8-1.7)$ & $1.2(0.8-1.7)$ & $1.2(0.8-1.7)$ \\
\hline Farmer father & $0.9(0.6-1.2)$ & $0.9(0.6-1.3)$ & $0.9(0.6-1.3)$ & $1.5(1.0-2.1)$ & $1.5(1.0-2.2)$ & $1.5(1.0-2.2)$ \\
\hline Age 30 working class & $1.4(1.0-2.0)$ & $1.4(1.0-2.0)$ & $1.4(1.0-1.9)$ & $1.9(1.2-3.0)$ & $1.9(1.1-3.0)$ & $1.8(1.1-3.0)$ \\
\hline Age 40 working class & $1.4(1.0-1.9)$ & $1.3(1.0-1.9)$ & $1.2(0.9-1.7)$ & $1.7(1.2-2.5)$ & $1.7(1.2-2.5)$ & $1.6(1.0-2.3)$ \\
\hline Age 50 working class & $1.3(0.9-1.8)$ & $1.2(0.9-1.7)$ & $1.2(0.9-1.6)$ & $1.7(1.2-2.4)$ & $1.5(1.0-2.1)$ & $1.4(1.0-2.0)$ \\
\hline Age 10 low area SES & $1.2(0.8-1.8)$ & $1.2(0.8-1.8)$ & $1.2(0.8-1.9)$ & $0.8(0.5-1.3)$ & $0.7(0.4-1.1)$ & $0.8(0.5-1.3)$ \\
\hline Age 30 low area SES & $1.3(0.9-1.9)$ & $1.1(0.7-1.7)$ & $1.0(0.6-1.7)$ & $0.9(0.5-1.5)$ & $0.7(0.4-1.3)$ & $0.7(0.4-1.2)$ \\
\hline Age 40 low area SES & $1.3(0.9-1.9)$ & $1.2(0.8-2.0)$ & $1.2(0.7-1.9)$ & $1.2(0.7-1.9)$ & $1.1(0.7-1.8)$ & $1.0(0.6-1.7)$ \\
\hline Age 50 low area SES & $1.7(1.2-2.5)$ & $1.6(1.0-2.4)$ & $1.4(0.9-2.2)$ & $1.6(1.1-2.5)$ & $1.5(1.0-2.3)$ & $1.4(0.9-2.2)$ \\
\hline
\end{tabular}

Note: First column within each race stratum is adjusted only for age. Model 2 is multivariate model that includes age at visit 1 , sex, center, paternal or subject social class measure, and area SES. A separate model is fitted for each life-course period. Models for adult social class include father's social class and father's having been a farmer. Models for father's social class or father's farming status do not include subjects' adult social class. Model 3 is model 2 plus diabetes mellitus and hypertension at visit 1 . The lowest tertile of the area SES score defines low area-level SES; the reference category is the highest tertile of area SES score. Area SES score was calculated by summing $z$ scores of area-level census attributes. 
Adjusting for area SES, center, father's social class, and farming, the association between social class at age 30 and CKD was attenuated by $4.2 \%$ to 1.9 (95\% CI, 1.1 to 3.0). Further adjustment for hypertension and diabetes mellitus reduced the OR by $14.7 \%$ to 1.8 (95\% CI, 1.1 to 3.0). The age-adjusted OR comparing lowest with highest tertile of area SES was greatest for age 50, for which it was 1.6 (95\% CI, 1.1 to 2.5). Unlike whites, African Americans whose fathers were farmers had 1.5 times the adjusted odds of CKD as those with nonfarmer fathers $(95 \% \mathrm{CI}$, 1.0 to 2.2); the strength of association was not attenuated by adjustment for diabetes and hypertension.

Table 4 lists associations of education and CKD. Not completing high school is associated with an increased odds of CKD compared with those with a college degree or more: among whites, the OR was 1.7 (95\% CI, 1.2 to 2.5), and among African Americans, the OR was 1.6 (95\% CI, 1.1 to 2.5). Further adjustment for area SES, center, father's education, and father being a farmer attenuated the association between education and CKD by $35 \%$ among whites and by $42 \%$ among African Americans. Adjustment for hypertension and diabetes mellitus all but eliminated the education association among both whites and African Americans.

Next, we formally tested for effect-measure modification between race and social class or education level. The only significant interaction term was between race and father having been a farmer $(P=0.07)$. Although the association of social class and education on CKD odds appeared to be stronger among African Americans than whites, all other interaction terms were greater than $P$ of 0.10 .

Several sensitivity analyses were conducted. Analyses were repeated first by using individual components of social class from the questionnaire. No individual component was associated significantly with CKD. We also investigated a possible dose-response relationship between increasing number of working class components with CKD. Among whites, there was no dose response by number of class components. Among African Americans, values for $P$ for trend were $0.05,0.03$, and 0.08 at ages 30,40 , and 50, respectively.

Associations using the outcome defined by only ICD-9 codes were consistent with those from the original outcome. Using only estimated GFR less than $45 \mathrm{~mL} / \mathrm{min} / 1.73 \mathrm{~m}^{2}(<0.75 \mathrm{~mL} / \mathrm{s} /$ $1.73 \mathrm{~m}^{2}$ ) as an outcome, most associations were close to the null value.

Finally, we calculated the odds of CKD associated with high school education, which was available for all subjects (including those who died or were lost to follow-up before they could complete the life-course socioeconomic questionnaire). Among whites, log-odds was $11 \%$ lower in the analysis data set than in the complete

Table 4. ORs and 95\% Cls of CKD Using Education Definition

\begin{tabular}{|c|c|c|c|c|c|c|}
\hline \multirow[b]{2}{*}{ Adjusted for } & \multicolumn{3}{|c|}{ Whites } & \multicolumn{3}{|c|}{ African Americans } \\
\hline & Age & $\begin{array}{c}\text { Model } 2 \\
\text { Confounders }\end{array}$ & $\begin{array}{c}\text { Model 3: } \\
\text { Model } 2+\text { Diabetes, } \\
\text { Hypertension }\end{array}$ & Age & $\begin{array}{c}\text { Model } 2 \\
\text { Confounders }\end{array}$ & $\begin{array}{c}\text { Model 3: } \\
\text { Model } 2 \text { + Diabetes, } \\
\text { Hypertension }\end{array}$ \\
\hline \multicolumn{7}{|c|}{ Father's education (y) } \\
\hline $0-8(v 12+)$ & $1.3(0.9-1.8)$ & $1.2(0.8-1.7)$ & $1.1(0.8-1.6)$ & $1.4(0.7-3.0)$ & $1.4(0.7-3.0)$ & $1.4(0.6-3.1)$ \\
\hline $9-11(v 12+)$ & $1.3(0.7-2.2)$ & $1.2(0.7-2.2)$ & $1.2(0.7-2.2)$ & $1.2(0.4-3.4)$ & $1.1(0.4-3.5)$ & $1.0(0.3-3.3)$ \\
\hline \multicolumn{7}{|c|}{ Subject's education $(\mathrm{y})$} \\
\hline $0-11(v 17+)$ & $1.7(1.2-2.5)$ & $1.4(0.9-2.2)$ & $1.1(0.7-1.6)$ & $1.6(1.1-2.5)$ & $1.3(0.8-2.1)$ & $0.8(0.5-1.3)$ \\
\hline $12-16(v 17+)$ & $1.3(1.0-1.9)$ & $1.2(0.9-1.7)$ & $1.1(0.8-1.6)$ & $1.6(1.0-2.5)$ & $1.4(0.9-2.3)$ & $1.3(0.8-2.1)$ \\
\hline \multicolumn{7}{|l|}{ Area SES } \\
\hline \multicolumn{7}{|c|}{ Age 10 low county } \\
\hline SES & $1.2(0.8-1.8)$ & $1.1(0.7-1.8)$ & $1.2(0.8-1.8)$ & $0.8(0.5-1.3)$ & $0.8(0.5-1.3)$ & $0.8(0.5-1.4)$ \\
\hline \multicolumn{7}{|l|}{ Age 50 low tract } \\
\hline SES & $1.7(1.2-2.5)$ & $1.5(1.0-2.4)$ & $1.4(0.9-2.2)$ & $1.6(1.1-2.5)$ & $1.5(0.9-2.3)$ & $1.4(0.9-2.3)$ \\
\hline
\end{tabular}

Note: First column within each race stratum is adjusted only for age. Model 2 is a multivariate model with adjusted age at visit 1 , sex, area SES, father's and subject's education, and center. Model 3 is model 2 plus diabetes mellitus and hypertension at visit 1 . 
cohort, whereas among African Americans, log odds was attenuated by $50 \%$.

\section{DISCUSSION}

We found that being a member of the working class was associated with CKD among the ARIC LCSES population, even at earlier stages of the adult life course. Results suggest that the strength of association between being working class and CKD is stronger among African Americans than whites. At later periods in the life course, area SES is associated with CKD. Individual education level also is associated with CKD, but adjustment for confounders and mediators reduced the strength of association. There were no associations between parental class or childhood area SES measures and CKD. Findings appear to have been driven by $I C D-9$ results, suggesting that the association is strongest among those with more severe illness that has come to clinical attention.

These findings are novel not only in using a life-course approach to assess the association between socioeconomic conditions and CKD, but also in our use of social class as an exposure. Most assessments of socioeconomic position use a continuous measure of SES, such as years of education or household income. ${ }^{16}$ Class advocates, such as Wright, favor using instruments that measure relationships of authority, decision making, ownership, and skill level. ${ }^{24,40}$ Social class, here dichotomized between those who have some degree of authority, control, ownership, or education and the working class that lacks these attributes, is robust to adjustment for multiple confounders and mediating factors. This indicates that the pathway relating social class to CKD may not operate entirely through hypertension and diabetes. Whereas education level is associated with CKD, this association is weakened after adjustment for multiple confounders.

This is the first study examining the relationship of individual and contextual social conditions with CKD across the life course. Whereas most studies of social determinants of CKD focus on race, there are notable exceptions. ${ }^{12}$ Merkin et $\mathrm{al}^{41}$ conducted an analysis focusing on area-level effects among ARIC cohort members, finding associations between low area-level SES and CKD among white men and African-American women; their analysis differed from ours in their using kidney function decline and their focus on area measures in only middle age, whereas we examined the relationship of CKD with social class and area measures across the life course. Krop et $\mathrm{al}^{42}$ conducted an analysis examining the association of income and education level with early kidney function decline among persons with diabetes in the original ARIC cohort study and observed similar associations with CKD. Klag et $\mathrm{al}^{43}$ found area-level median income to be associated with elevated serum creatinine level in the Multiple Risk Factors Intervention Trial cohort. A Swedish casecontrol study by Fored et $\mathrm{al}^{44}$ found unskilled manual labor and low educational attainment to be associated with CKD. Recently, Martins et $\mathrm{al}^{45}$ reported an association between poverty level and microalbuminuria in the Third National Health and Nutrition Examination Survey; as in our analysis, this association was independent of sex, race, age, diabetes, and hypertension.

Several other studies using ESRD as an outcome found results consistent with our own. Perneger et $\mathrm{al}^{46}$ found income, Medicaid coverage, and missing teeth to be associated with ESRD in the mid-Atlantic region of the United States. Byrne et $\mathrm{al}^{47}$ found associations among whites between area-level income and ESRD in New York State, but not among African Americans; however, their study was conducted using data from the 1980s and was stratified into 12 subpopulations, limiting power.

Our study has several limitations. First, results reported here are likely to be underestimates of the true effect of social class and area SES on CKD odds, suggested by results of sensitivity analyses comparing the LCSES and full cohorts. If social conditions are associated with CKD, subjects with adverse socioeconomic circumstances may have died before participating in the ancillary study. Another source of underestimation could be the use of county-based measures of childhood area-level SES. Census tracts are the preferred level of analysis in contextual exposures in health research, ${ }^{28,48}$ but tracts did not cover the entire United States until the 1990 census. ${ }^{49}$ Because the county captures regional, rather than neighborhood, information, significant misclassification of salient area-level attributes may occur. This may explain the lack of association between childhood area SES and 
CKD. Results also would be underestimated if social class or education level were subject to nondifferential misclassification because of imprecision in measuring social class or recall bias. Misclassification would only bias results away from the null if those with CKD: (1) knew they had CKD and (2) were more likely than those without CKD to mistakenly report adverse socioeconomic conditions. Although we do not have data for test-retest characteristics of participants, differential misclassification bias is an unlikely scenario given the low awareness of CKD in the general population. ${ }^{5,50}$

Second, many subjects were missing census tracts at ages 30 and 40 . We used a multiple imputation technique to adjust for these missing data. The validity of the multiple imputation approach is contingent upon the data being missing at random, given a set of available information. $^{51,52}$ We believe missingness is accounted for largely by available variables, which included race, occupation, age, and health behaviors. Analyses that include only the original nonimputed data yielded similar results from those reported here, although the former tended to be closer to the null value and lower precision.

Third, we used race-specific tertiles to define area-level SES categories. However, whites and African Americans had distinctly different arealevel scores, with little overlap; this is not surprising given the history of segregation in the United States. ${ }^{53}$ Racial and economic segregation into low SES areas might account for some of the racial disparities in kidney disease, but we could not investigate this hypothesis using the available data.

Finally, adjustment for causal intermediates to estimate the direct effect of socioeconomic conditions on CKD is subject to limitations. By the direct effect, we mean the effect not transmitted through the effect of social factors on these other chronic conditions. ${ }^{54}$ The unbiased estimation of the direct effect assumes there are no unmeasured confounders between these intermediates and the outcome $\mathrm{e}^{55}$ and there is no interaction between exposure and intermediates in the causation of the outcome. ${ }^{56}$ If these assumptions hold, adjustment for diabetes and hypertension should have attenuated the estimated exposure measures. However, there was little change in ORs when a class-based definition was used, which is consistent with social class being associated with CKD independently of diabetes and hypertension.

Our study offers some implications of immediate importance. First, social class is important among both whites and African Americans; the latter group shows both a stronger association with social class and a greater absolute burden of later-stage kidney disease. Our study lends support to a focus on social factors that might account for racial disparities in CKD and ESRD. Although the association between education and CKD was largely eliminated upon adjustment for confounding and mediating attributes, the social class measures were robust to such adjustment, especially among African Americans.

In conclusion, we show that social class may be an antecedent cause of CKD and appears to be independent of more proximate causes. The mechanisms involved remain to be determined. Being a member of the working class in early adulthood is at least as harmful to the kidneys as later-life working class status; however, this association appears to be independent of hypertension and diabetes. If the association between social conditions and CKD truly is causal, amelioration of CKD disparities may require considerable political will and changes in policy. Policies that focus on individual behavior alone may not be sufficient to stem the tide of kidney disease.

\section{APPENDIX}

\section{CKD Definition Based on ICD-9 Codes}

CKD defined by hospital discharge diagnoses included the following ICD-9 codes: $250.4 \mathrm{x}$, 403.x, 581.x, 582.x, 583.x, 585.x, 586.x, 587.x, 588.x, v42.0, v45.1, 39.95, or 54.98 at any time through the end of 2002 (participants with ICD-9 codes for uremia, acute renal failure, and posttraumatic renal failure were excluded [codes 584.x, 788.9x, 958.5x, and 584.0x]).

\section{Model Specifications for Multiple Imputations}

Stata version 9.0 (Stata Corp, College Station, TX) user written multiple imputation programs specifying 10 iterations and 5 imputations were used. ${ }^{52,58}$ Predictor variables used in the imputation included father farming; working class sta- 
tus for father and at ages 30, 40, 50, and at last job; hypertension and diabetes status at ARIC baseline visit; sex; age; race; drinking and cigarette consumption; baseline body mass index; baseline serum high-density lipoprotein cholesterol level; ARIC study center; mother's, father's, and subject's educational attainment; and available area-level attributes and scores for childhood and ages 30, 40, and 50.

\section{REFERENCES}

1. US Renal Data System: USRDS 2005 Annual Data Report. The National Institutes of Health, National Institute of Diabetes and Digestive and Kidney Diseases, Bethesda, MD, 2005

2. Coresh J, Astor B, Sarnak MJ: Evidence for increased cardiovascular disease risk in patients with chronic kidney disease. Curr Opin Nephrol Hypertens 13:73-81, 2004

3. Foley RN, Murray AM, Li S, et al: Chronic kidney disease and the risk for cardiovascular disease, renal replacement, and death in the United States Medicare population, 1998 to 1999. J Am Soc Nephrol 16:489-495, 2005

4. Coresh J, Astor BC, Greene T, Eknoyan G, Levey AS: Prevalence of chronic kidney disease and decreased kidney function in the adult US population: Third National Health and Nutrition Examination Survey. Am J Kidney Dis 41:112,2003

5. Coresh J, Byrd-Holt D, Astor BC, et al: Chronic kidney disease awareness, prevalence, and trends among US adults, 1999 to 2000. J Am Soc Nephrol 16:180-188, 2005

6. Coresh J, Wei GL, McQuillan G, et al: Prevalence of high blood pressure and elevated serum creatinine level in the United States: Findings from the Third National Health and Nutrition Examination Survey (1988-1994). Arch Intern Med 161:1207-1216, 2001

7. Culleton BF, Larson MG, Evans JC, et al: Prevalence and correlates of elevated serum creatinine levels: The Framingham Heart Study. Arch Intern Med 159:1785-1790, 1999

8. Jones CA, Francis ME, Eberhardt MS, et al: Microalbuminuria in the US population: Third National Health and Nutrition Examination Survey. Am J Kidney Dis 39:445459,2002

9. Jones CA, McQuillan GM, Kusek JW, et al: Serum creatinine levels in the US population: Third National Health and Nutrition Examination Survey. Am J Kidney Dis 32:992999, 1998

10. Parazella M: Chronic kidney disease: The silent epidemic. Hosp Physician 39:15-17, 2003

11. Cass A, Cunningham J, Snelling P, Wang Z, Hoy W: Exploring the pathways leading from disadvantage to endstage renal disease for indigenous Australians. Soc Sci Med 58:767-785, 2004

12. Shoham DA, Vupputuri S, Kshirsagar AV: Chronic kidney disease and life course socioeconomic status: A review. Adv Chronic Kidney Dis 12:56-63, 2005

13. Martins D, Tareen N, Norris KC: The epidemiology of end-stage renal disease among African Americans. Am J Med Sci 323:65-71, 2002
14. Cooper RS, Kaufman JS, Ward R: Race and genomics. N Engl J Med 348:1166-1170, 2003

15. Krieger N, Williams DR, Moss NE: Measuring social class in US public health research: Concepts, methodologies, and guidelines. Annu Rev Public Health 18:341-378, 1997

16. Lynch J, Kaplan G: Socioeconomic position, in Berkman L, Kawachi I (eds): Social Epidemiology. New York, NY, Oxford, 2000, pp 13-35

17. Oakes JM, Rossi PH: The measurement of SES in health research: Current practice and steps toward a new approach. Soc Sci Med 56:769-784, 2003

18. Davey Smith G, Hart C, Blane D, Gillis C, Hawthorne D: Lifetime socioeconomic position and mortality: Prospective observational study, in Davey Smith G (ed): Health Inequalities: Lifecourse Approaches. Bristol, UK, Policy, 2003, pp 153-169

19. Davey Smith G, Hart C, Hole D, et al: Education and occupational social class: Which is the more important indicator of mortality risk?, in Davey Smith G (ed): Health Inequalities: Lifecourse Approaches. Bristol, UK, Policy, 2003, pp 171-189

20. Wilkinson R: Unhealthy Societies: The Afflictions of Inequality. New York, NY, Routledge, 1996

21. Bourdieu P: Distinction. Cambridge, MA, Harvard, 1984

22. Wohlfarth T: Socioeconomic inequality and psychopathology: Are socioeconomic status and social class interchangeable? Soc Sci Med 45:399-410, 1997

23. Horan P: Is status attainment research atheoretical? Am Sociol Rev 43:534-540, 1978

24. Wright EO: Class Counts. New York, NY, Cambridge, 1996

25. Diez-Roux A: Bringing context back into epidemiology: Variables and fallacies in multilevel analysis. Am J Public Health 88:216-222, 1998

26. Krieger N: Epidemiology and the web of causation: Has anyone seen the spider? Soc Sci Med 39:887-903, 1994

27. Diez Roux AV, Merkin SS, Arnett D, et al: Neighborhood of residence and incidence of coronary heart disease. N Engl J Med 345:99-106, 2001

28. Krieger N, Chen JT, Waterman PD, Soobader MJ, Subramanian SV, Carson R: Choosing area based socioeconomic measures to monitor social inequalities in low birth weight and childhood lead poisoning: The Public Health Disparities Geocoding Project (US). J Epidemiol Community Health 57:186-199, 2003

29. O'Campo P, Xue X, Wang MC, Caughy M: Neighborhood risk factors for low birthweight in Baltimore: A multilevel analysis. Am J Public Health 87:1113-1118, 1997

30. Blane D: The life course, the social gradient, and health, in Marmot M, Wilkinson R (eds): Social Determinants of Health. Oxford, England, Oxford, 1999, pp 64-80

31. Kuh D, Power C, Blane D, Bartley ML: Social pathways between childhood and adult health, in Kuh D, Ben-Shlomo Y (eds): A Life Course Approach to Chronic Disease Epidemiology. Oxford, NY, Oxford, 1997, pp 169200

32. Barker D: Fetal and Infant Origins of Adult Diseases. London, UK, BMJ, 1992 
33. ARIC Investigators: The Atherosclerosis Risk in Communities (ARIC) Study: Design and objectives. Am J Epidemiol 129:687-702, 1989

34. Whitsel EA, Rose KM, Wood JL, Henley AC, Liao D, Heiss G: Accuracy and repeatability of commercial geocoding. Am J Epidemiol 160:1023-1029, 2004

35. Szelény S: The "woman problem" in stratification theory and research, in Grusky DB (ed): Social Stratification. Boulder, CO, Westview, 2001, pp 681-688

36. Levey AS, Green T, Kusek JW, Beck GJ, Group MS: A simplified equation to predict glomerular filtration rate from serum creatinine. J Am Soc Nephrol 11:155A, 2000 (abstr)

37. Astor BC, Arnett DK, Brown A, Coresh J: Association of kidney function and hemoglobin with left ventricular morphology among African Americans: The Atherosclerosis Risk in Communities (ARIC) Study. Am J Kidney Dis 43:836-845, 2004

38. Go AS, Chertow GM, Fan D, McCulloch CE, Hsu CY: Chronic kidney disease and the risks of death, cardiovascular events, and hospitalization. N Engl J Med 351:12961305, 2004

39. National Kidney Foundation: K/DOQI Clinical Practice Guidelines for Chronic Kidney Disease: Evaluation, classification, and stratification. Am J Kidney Dis 39:S1S246, 2002 (suppl 2)

40. Wright EO: Classes. London, UK, Verso, 1989

41. Merkin SS, Coresh J, Roux AV, Taylor HA, Powe NR: Area socioeconomic status and progressive CKD: The Atherosclerosis Risk in Communities (ARIC) Study. Am J Kidney Dis 46:203-213, 2005

42. Krop JS, Coresh J, Chambless LE, et al: A communitybased study of explanatory factors for the excess risk for early renal function decline in blacks vs whites with diabetes: The Atherosclerosis Risk in Communities study. Arch Intern Med 159:1777-1783, 1999

43. Klag MJ, Whelton PK, Randall BL, Neaton JD, Brancati FL, Stamler J: End-stage renal disease in AfricanAmerican and white men: 16-Year MRFIT findings. JAMA 277:1293-1298, 1997
44. Fored CM, Ejerblad E, Fryzek JP, et al: Socioeconomic status and chronic renal failure: A populationbased case-control study in Sweden. Nephrol Dial Transplant 18:82-88, 2003

45. Martins D, Tareen N, Zadshir A, et al: The association of poverty with the prevalence of albuminuria: Data from the Third National Health and Nutrition Examination Survey (NHANES III). Am J Kidney Dis 47:965-971, 2006

46. Perneger TV, Whelton PK, Klag MJ: Race and endstage renal disease. Socioeconomic status and access to health care as mediating factors. Arch Intern Med 155:12011208, 1995

47. Byrne C, Nedelman J, Luke RG: Race, socioeconomic status, and the development of end-stage renal disease. Am J Kidney Dis 23:16-22, 1994

48. Diez-Roux AV, Nieto FJ, Muntaner C, et al: Neighborhood environments and coronary heart disease: A multilevel analysis. Am J Epidemiol 146:48-63, 1997

49. Krieger N: A century of census tracts: Health \& the body politic (1906-2006). J Urban Health 83:355-361, 2006

50. Nickolas TL, Frisch GD, Opotowsky AR, Arons R, Radhakrishnan J: Awareness of kidney disease in the US population: Findings from the National Health and Nutrition Examination Survey (NHANES) 1999 to 2000. Am J Kidney Dis 44:185-197, 2004

51. Royston P: Multiple imputation of missing values. STATA J 4:227-241, 2004

52. Schafer JL, Graham JW: Missing data: Our view of the state of the art. Psychol Methods 7:147-177, 2002

53. Massey DS, Denton NA: American Apartheid: Segregation and the Making of the Underclass. Cambridge, MA, Harvard, 1993

54. Robins JM, Greenland S: Identifiability and exchangeability for direct and indirect effects. Epidemiology 3:143155,1992

55. Cole SR, Hernan MA: Fallibility in estimating direct effects. Int J Epidemiol 31:163-165, 2002

56. Kaufman JS, Maclehose RF, Kaufman S: A further critique of the analytic strategy of adjusting for covariates to identify biologic mediation. Epidemiol Perspect Innov 1:4, 2004 